\title{
ЦВЕТНЫЕ РЕВОЛЮЦИИ И ПОЛИТИЧЕСКИЙ КРИЗИС В УКРАИНЕ
}

\begin{abstract}
Аннотация. Настоящая статья посвящена исследованию современных форм, методов и технологий цветных революций как инструментов демократического преобразования традиционных обществ и демонтажа политических режимов, а аткже их роли в осуществлении антиконституционного переворота в Украине. Автор подчеркивает, что в современных условиях, к сожалению, нельзя исключать перенесения опыта организации украинского переворота на российскую территорию. Подобное мы уже наблюдали с революциями Арабской весны, когда схемы иветных революций "обкатывались" на одной стране, а далее, в усовершенствованном и модифицированном виде переносились на следующую страну. Методологической основой исследования является системный, структурно-функциональный, сравнительно-политический подходы, методы анализа, синтеза, индукции, дедукции, наблюдения. Цветные революции как отлаженные политические технологии отличаются высокой результативностью в практическом применении. Вместе с тем, относительно высокая шаблонность технологий цветных революций может приводить к значительному снижению их эффективности. Однако широкое распространение коммуникационных и информационных технологий формирует благоприятные условия для появления новых и совершенствования старых методик управления политическими процессами в различных странах.
\end{abstract}

Ключевые слова: геополитика, Россия, мировая политика, внешняя политика США, государственный переворот, дипломатия, интересы, государство, безопасность, «цветные революции».

Review: This article is devoted to the study of modern forms, methods and technologies of color revolutions as the instruments of democratic transformation of traditional societies and the dismantling of political regimes. The author emphasizes that in the present conditions, unfortunately, we can not exclude the possibility of transfer of the experience of Ukrainian revolution organization to Russia. We could observe this situation during the events of the Arab Spring, when the scheme of color revolutions had been given "trial runs" in one country, and then, improved and modified, was transferred to another country.The methodological basis of the research contains the systems approach, the structural and functional and comparative-political approaches, the methods of analysis, synthesis, induction, deduction, observation. Color revolutions as efficient political technologies are very effective. At the same time, the stereotyped character of color revolutions technologies can lead to a significant decrease of their effectiveness. However, the widespread communication and information technologies create favorable conditions for the emergence of new and the improvement of old methods of political processes management in different countries.

Keywords: interests, diplomacy, coup d'état, U.S. foreign policy, world politics, Russia, geopolitics, state, security, color revolutions.

$\mathrm{C}$ овременные инструменты и технологии принудительного демонтажа политических режимов в современном мире происходят по определенному повторяющемуся сценарию, который имеет свой первоисточник - это книга хорошо известного американского политолога Джина Шарпа «От диктатуры к демократии» [1]. Шарп выделяет следующие принципы развития цветной революции:

- «Наличие сравнительно большой и политически активной социальной группы, считающей, что ее жизненно важные потребности не удовлетворены, а интересы ущемляются.

- Неудовлетворенность широких слоев населения уровнем жизни и предлагаемыми реформами.
- Слабый или недостаточный контроль над основными источниками силы власти, например, над СМИ.

- Наличие в правящей «верхушке» сторонников оппозиции.

- Способность и желание группы, находящейся у власти, отстаивать и защищать свои интересы» [1].

Вместо насилия, в случае цветных революций, борьба ведется психологическим, социальным, экономическим и политическим оружием, применяемым общественными институтами и населением. Однако возможны провокации, например, убийства собственных сторонников, списываемые на власть.

Ф. Фукуяма в своих работах [2] отмечает, что в случаях с цветными революциями решающую 
роль играет внешняя поддержка. Американский исследователь подробно раскрывает условия, необходимые для реализации концепции транзита демократий:

- «Наличие сильных и сплоченных групп, способных стать инициатором политических перемен и противостоять режиму

- Наличие в стране каких-либо признаков авторитарного режима. Разумеется, такая форма правления вызывает недовольство среди населения и создает прочную базу для протестного движения.

- Наличие в стране националистических настроений, желание присоединиться к западному обществу и согласие ради этого на получение помощи от США» [2].

Анализ событий на Украине показывает, что развитие ситуации в этой стране в 2013-14 гг. практически в точности повторяло классический сценарий цветных революций.

Очевидно, что переворот на Украине осуществлялся при широкой политической, дипломатической, материальной и военно-технической помощи Запада и США. Подготовка к перевороту на Украине началась заранее. Были широко представлены технологии информационно-психологических войн. Можно было наблюдать действия, направленные на усиление конфронтации между украинским и русским народами. В течение многих лет в сознание украинских граждан внедрялись представления о том, что наши народы имеют совершенно разные корни и что развивались они разными путями, проводилась активная кампания по разрушению нашего общего исторического прошлого.

В то же время на Западе была развернута мощная информационная кампания против России.

A.В. Манойло также отмечает, что события на Украине полностью подпадают под классические схемы цветных революций. Государственный переворот был проведен в условиях нарастающей политической нестабильности, с использованием молодежного протестного движения и с применением таких методов оказания давления, как политический шантаж, выдвижение требований и ультиматумов к действующей власти [9].

Также использовались маргинальные группы, в том числе террористической направленности и экстремистского содержания - профашистские экстремистские группировки и антироссийские группы украинских националистов.

Однако нужно заметить, что Запад и США не учли, а, точнее, просто проигнорировали интересы России на Украине. Было очевидно, что Россия станет защищать интересы русскоязычного населения и собственных граждан, а также не захочет потерять важного экономического и политического партнера в лице Украины. Судя по всему, они надеялись, что события будут развиваться по стандартному сценарию, и все решится довольно быстрым и мирным путем.

Президент Московской ассоциации политической науки Т.В. Евгеньева отмечает, что все политические технологии, которые использовались на Украине, опирались, прежде всего, на механизм идентификации. Никакие политические технологии не будут работать, если они не опираются на знание объективной ситуации - не только политической, но и политико-психологической. Украина никогда не была идентифицирована в качестве единой национально-государственной общности, ни до войны, когда присоединили Западную Украину, ни после того как туда вошел Крым. Если в расколотой нации нет возможности сформировать некую единую национальную идентичность с помощью позитивных оснований, то используется негативная идентификация. Это и есть главная технология, которая использовалась всеми участниками. Её суть очень проста - это конструирование образа врага. У этого образа врага есть две ипостаси - внутренняя и внешняя. Внутренняя ипостась - коррумпированные чиновники во главе с Януковичем, а также по ассоциации с ними и «Партия регионов», которая позиционируется как партия этих самых чиновников. Вторая, внешняя ипостась образа врага, - это Россия, которая якобы стоит за Януковичем, и не только препятствует подписанию соглашения с Евросоюзом, но даже хочет захватить или оккупировать Украину.

Официальная позиция России по поводу цветных революций и угроз международной и национальной безопасности, связанных с этим явлением, четко прослеживается в выступлениях С. Лаврова и В. Чуркина. Они неоднократно заявляли, что Российская Федерация не занимается сменой режимов и организацией цветных революций, "тем более с коричневым оттенком, как на Украине" [3]. Также, С. Лавров отмечал, что Россия не намерена вмешиваться во внутренние дела Грузии в связи с возможным подписанием соглашения об ассоциации с Европейским союзом.

В ходе проведенного анализа выяснилось, что на законодательном, нормативном уровне внимание цветным революциям уделяется весьма небольшое. Однако следует отметить, что тенденция к осознанию роли цветных революций в мировой политике и международных отношениях все же присутствует, цветные революции довольно быстро входят в российский политический дискурс.

Например, В. Путин в послании к Федеральному собранию в 2014 году отметил тот факт, что цветные революции получили значительное распространение, и России, если, конечно, она хочет 
занять достойное место на международной арене, следует научиться им успешно противостоять.

Следует отметить, что феномен цветных революций очень тесно связан с информационно-психологическим противоборством. В Военной доктрине Российской Федерации [4] признается, что одной из характерных черт современных военных конфликтов является «усиление роли информационного противоборства», однако на протяжении всего документа, в списке задач и целей, нет ни слова о цветных революциях или информационнопсихологических операциях.

В Стратегии национальной безопасности Российской Федерации [5] говорится об усилении угроз национальной безопасности РФ: «усилится глобальное информационное противоборство, возрастут угрозы стабильности индустриальных и развивающихся стран мира, их социально-экономическому развитию и демократическим институтам».

В Концепции внешней политики Российской Федерации упоминается «мягкая сила». Выделяется тенденция к ее деструктивному и противоправному использованию «в целях оказания политического давления на суверенные государства, вмешательства в их внутренние дела, дестабилизации там обстановки, манипулирования обществен- ным мнением и сознанием, в том числе в рамках финансирования гуманитарных проектов, связанных с защитой прав человека за рубежом» [6].

Важно, чтобы в России как можно скорее были выработаны собственные схемы противодействия цветным революциям, так как без этого она не сможет защитить свои национальные интересы от новых технологий внешнего вмешательства.

"Очевидно, что современные вызовы и угрозы требуют отказа от архаичной логики геополитических игр с нулевым результатом. От попыток навязывания другим народам собственных рецептов и ценностных ориентиров, в том числе путем цветных революций", - подчеркнул Президент РФ B. Путин во время III Московской конференции по международной безопасности [7].

Автор придерживается мнения, что цветные революции возникают, в том числе, и из-за реально существующих в обществе противоречий политического или социального характера, которые действующая власть не в состоянии своевременно разрешить. В формировании объективных предпосылок цветных революций и государственных переворотов роль «внешнего фактора» незначительна, однако его значение в обеспечении победы сторонников «цветной» идеологии в подавляющем большинстве случаев решающее.

\section{Библиография:}

1. Шарп Д. От диктатуры к демократии: Стратегия и тактика освобождения. // Пер. с англ. Н. Козловской. М.: Новое издательство, 2005. 84 с.

2. Фукуяма Ф. Америка на распутье. М., 2008. 288 с. С. 182-183.

3. Лавров: Москва не занимается организацией «цветных революций». URL: http://itar-tass.com/politika/1169286 (дата обращения: 21.03.2015)

4. Военная доктрина Российской Федерации URL: http://www.kremlin.ru/supplement/461 (дата обращения: 20.03.2015)

5. Стратегия национальной безопасности Российской Федерации до 2020 года URL: http://www.kremlin.ru/ supplement/424 (дата обращения: 20.03.2015)

6. Концепция внешней политики Российской Федерации URL: http://www.kremlin.ru/acts/news/785 (дата обращения: 20.03.2015)

7. Игры с нулевым результатом. URL: http://www.rg.ru/2014/05/23/konferenciya-site.html (дата обращения: 21.03.2015)

8. Манойло А.В. Актуальные вопросы модернизации современной культурно-цивилизационной теории управления международными конфликтами. // Национальная безопасность / nota bene. - 2011. - № 4. - C. 60-66.

9. Манойло А.В. Украинский кризис и «управляемый хаос»: след «цветных революций» Арабской Весны. // Власть. 2014. №4. С. 24-28.

10. Карпович О.Г. Цветная «революция зонтиков» в Гонконге: начало «Китайской Весны» // Национальная безопасность / nota bene. - 2014. - 6. - C. 990 - 996. DOI: 10.7256/2073-8560.2014.6.13602.

11. Бородинов Е.Н. Территориальный раскол и конфликт элит в Украине // Тренды и управление. - 2014. - 1. C. 51 - 62. DOI: 10.7256/2307-9118.2014.1.11739.

12. Бородинов Е.Н. Причины и следствия государственного переворота на Украине // Мировая политика. - 2014. 3. - C. 36 - 59. DOI: 10.7256/2409-8671.2014.3.11501. URL: http://www.e-notabene.ru/wi/article_11501.html

13. Карякин В.В. Проблемы российской политологии и пути их решения // Конфликтология / nota bene. - 2015. 3. - C. 243 - 248. DOI: 10.7256/2409-8965.2015.3.16125.

14. Карпович О.Г. Риски и угрозы цветной революции в России // Политика и Общество. - 2015. - 1. - С. 107 - 115. DOI: 10.7256/1812-8696.2015.1.14141.

15. Гушер А.И. Вызовы и угрозы безопасности России // Мировая политика. - 2014. - 1. - C. 64 - 75. DOI: 10.7256/24098671.2014.1.10748. URL: http://www.e-notabene.ru/wi/article_10748.html

16. Цатурян С.А., Джавлах К.С. Украина 2014: техника и предварительные итоги государственного переворота // Тренды и управление. - 2014. - 1. - С. 42 - 50. DOI: 10.7256/2307-9118.2014.1.12387.

17. Калачев Д.Н. Основные направления сотрудничества России и НАТО // Тренды и управление. - 2015. - 1. - С. 36 43. DOI: 10.7256/2307-9118.2015.1.13712. 
18. Гушер А.И. Кризис на Украине: геополитические и геостратегические аспекты // Мировая политика. - 2014. 4. - C. 79 - 89. DOI: 10.7256/2409-8671.2014.4.11605. URL: http://www.e-notabene.ru/wi/article_11605.html

19. Буневич Д.С. Крымский кризис 2014 года и создание новой архитектуры международных отношений // Конфликтология / nota bene. - 2015. - 2. - C. 133 - 139. DOI: 10.7256/2409-8965.2015.2.14333.

20. Будаев А.В. Основные подходы к использованию «мягкой силы» в интересах реализации внешней политики Российской Федерации // Тренды и управление. - 2014. - 2. - С. 175 - 187. DOI: 10.7256/2307-9118.2014.2.11784.

21. Спиридонов В.В. Экономические причины политического конфликта на Украине // Мировая политика. - 2014. 4. - C. 45 - 78. DOI: 10.7256/2409-8671.2014.4.11528. URL: http://www.e-notabene.ru/wi/article_11528.html

22. Филиппов В.Р. Сильванус Олимпио - первая жертва «Франсафрик» // Политика и Общество. - 2015. - 8. - С. 1014 1025. DOI: 10.7256/1812-8696.2015.8.16040.

23. Вепринцев В.Б. Влияние информационной составляющей на взаимодействие геополитических субъектов // Мировая политика. - 2015. - 1. - С. 192 - 212. DOI: 10.7256/2409-8671.2015.1.12621. URL: http://www.e-notabene.ru/ wi/article_12621.html

24. Калачев Д.Н. Эволюция отношений сотрудничества между Россией и НАТО // Тренды и управление. - 2015. - 1. C. 23 - 30. DOI: 10.7256/2307-9118.2015.1.14065.

25. Карпович О.Г. Цветные революции как инструмент системной дестабилизации политических режимов: угрозы и вызовы для России // Национальная безопасность / nota bene. - 2015. - 1. - C. 73 - 87. DOI: 10.7256/20738560.2015.1.14142.

\section{References (transliterated):}

1. Sharp D. Ot diktatury k demokratii: Strategiya i taktika osvobozhdeniya. // Per. s angl. N. Kozlovskoi. M.: Novoe izdatel'stvo, 2005. $84 \mathrm{~s}$.

2. Fukuyama F. Amerika na rasput'e. M., 2008. 288 s. S. 182-183.

3. Lavrov: Moskva ne zanimaetsya organizatsiei «tsvetnykh revolyutsii». URL: http://itar-tass.com/politika/1169286 (data obrashcheniya: 21.03.2015)

4. Voennaya doktrina Rossiiskoi Federatsii URL: http://www.kremlin.ru/supplement/461 (data obrashcheniya: 20.03.2015)

5. Strategiya natsional'noi bezopasnosti Rossiiskoi Federatsii do 2020 goda URL: http://www.kremlin.ru/supplement/424 (data obrashcheniya: 20.03.2015)

6. Kontseptsiya vneshnei politiki Rossiiskoi Federatsii URL: http://www.kremlin.ru/acts/news/785 (data obrashcheniya: 20.03.2015)

7. Igry s nulevym rezul'tatom. URL: http://www.rg.ru/2014/05/23/konferenciya-site.html (data obrashcheniya: 21.03.2015)

8. Manoilo A.V. Aktual'nye voprosy modernizatsii sovremennoi kul'turno-tsivilizatsionnoi teorii upravleniya mezhdunarodnymi konfliktami. // Natsional'naya bezopasnost' / nota bene. - 2011. - № 4. - C. 60-66.

9. Manoilo A.V.Ukrainskii krizis i «upravlyaemyi khaos»: sled «tsvetnykh revolyutsii» Arabskoi Vesny. // Vlast'. 2014 . №4. S. 24-28.

10. Karpovich O.G. Tsvetnaya «revolyutsiya zontikov» v Gonkonge: nachalo «Kitaiskoi Vesny» // Natsional'naya bezopasnost' / nota bene. - 2014. - 6. - C. 990 - 996. DOI: 10.7256/2073-8560.2014.6.13602.

11. Borodinov E.N. Territorial'nyi raskol i konflikt elit v Ukraine // Trendy i upravlenie. - 2014. - 1. - C. 51 - 62. DOI: 10.7256/2307-9118.2014.1.11739.

12. Borodinov E.N. Prichiny i sledstviya gosudarstvennogo perevorota na Ukraine // Mirovaya politika. - 2014. - 3. - C. 36 59. DOI: 10.7256/2409-8671.2014.3.11501. URL: http://www.e-notabene.ru/wi/article_11501.html

13. Karyakin V.V. Problemy rossiiskoi politologii i puti ikh resheniya // Konfliktologiya / nota bene. - 2015. - 3. - C. 243 - 248. DOI: 10.7256/2409-8965.2015.3.16125.

14. Karpovich 0.G. Riski i ugrozy tsvetnoi revolyutsii v Rossii // Politika i Obshchestvo. - 2015. - 1. - C. 107 - 115. DOI: 10.7256/1812-8696.2015.1.14141.

15. Gusher A.I. Vyzovy i ugrozy bezopasnosti Rossii // Mirovaya politika. - 2014. - 1. - C. 64 - 75. DOI: 10.7256/24098671.2014.1.10748. URL: http://www.e-notabene.ru/wi/article_10748.html

16. Tsaturyan S.A., Dzhavlakh K.S. Ukraina 2014: tekhnika i predvaritel'nye itogi gosudarstvennogo perevorota // Trendy i upravlenie. - 2014. - 1. - C. 42 - 50. DOI: 10.7256/2307-9118.2014.1.12387.

17. Kalachev D.N. Osnovnye napravleniya sotrudnichestva Rossii i NATO // Trendy i upravlenie. - 2015. - 1. - C. 36 - 43. DOI: $10.7256 / 2307-9118.2015 .1 .13712$.

18. Gusher A.I. Krizis na Ukraine: geopoliticheskie i geostrategicheskie aspekty // Mirovaya politika. - 2014. - 4. - C. 79 - 89. DOI: 10.7256/2409-8671.2014.4.11605. URL: http://www.e-notabene.ru/wi/article_11605.html

19. Bunevich D.S. Krymskii krizis 2014 goda i sozdanie novoi arkhitektury mezhdunarodnykh otnoshenii // Konfliktologiya / nota bene. - 2015. - 2. - C. 133 - 139. DOI: 10.7256/2409-8965.2015.2.14333.

20. Budaev A.V. Osnovnye podkhody k ispol'zovaniyu «myagkoi sily» v interesakh realizatsii vneshnei politiki Rossiiskoi Federatsii // Trendy i upravlenie. - 2014. - 2. - C. 175 - 187. DOI: 10.7256/2307-9118.2014.2.11784.

21. Spiridonov V.V. Ekonomicheskie prichiny politicheskogo konflikta na Ukraine // Mirovaya politika. - 2014. - 4. - C. 45 78. DOI: 10.7256/2409-8671.2014.4.11528. URL: http://www.e-notabene.ru/wi/article_11528.html

22. Filippov V.R. Sil'vanus Olimpio - pervaya zhertva «Fransafrik» // Politika i Obshchestvo. - 2015. - 8. - C. 1014 - 1025. DOI: $10.7256 / 1812-8696.2015 .8 .16040$.

23. Veprintsev V.B. Vliyanie informatsionnoi sostavlyayushchei na vzaimodeistvie geopoliticheskikh sub"ektov // Mirovaya politika. 2015. - 1. - C. 192 - 212. DOI: 10.7256/2409-8671.2015.1.12621. URL: http://www.e-notabene.ru/wi/article_12621.html

24. Kalachev D.N. Evolyutsiya otnoshenii sotrudnichestva mezhdu Rossiei i NATO // Trendy i upravlenie. - 2015. - 1. C. 23 - 30. DOI: 10.7256/2307-9118.2015.1.14065.

25. Karpovich O.G. Tsvetnye revolyutsii kak instrument sistemnoi destabilizatsii politicheskikh rezhimov: ugrozy i vyzovy dlya Rossii // Natsional'naya bezopasnost' / nota bene. - 2015. - 1. - C. 73 - 87. DOI: 10.7256/2073-8560.2015.1.14142. 